\title{
Sedentary Behavior, Number of Steps and Health
}

\section{Sedanter Davranış, Adım Sayısı ve Sağlık}

S. Can

0000-0003-1931-2226

Geliș Tarihi / Date Received: 06.07.2018

Kabul Tarihi / Date Accepted: 19.09.2018

Yayın Tarihi/Published Online: 03.12.2018

\section{Yazışma Adresi /}

Corresponding Author:

Sema Can

Hitit Üniversitesi, Spor

Bilimleri Fakültesi, Çorum,

Turkey

E-mail: semacan@hitit.edu.tr (C)2019 Türkiye Spor Hekimleri Derneği. Tüm hakları saklıdır.

\author{
Sema Can \\ Faculty of Sport Sciences, Hitit University, Çorum, Turkey
}

\begin{abstract}
Long-term sedentary or inactive lifestyle is one of the risk factors that negatively affect a healthy and quality life. In public health campaigns around the world, physical activity (PA) proposals are being made to prevent the sedentary lifestyle. Among public health campaigns around the world, physical activity (PA) proposals; primarily "walking" is the leading one. The walking can be accomplished easily in daily life, without any cost, material or equipment. Adults are advised to reach 10000 steps per day but reaching 10000 steps in a single activity duration is unapproachable. Therefore, accordance with the recommendations of the PA guidelines, a moderate activity plan can be applied, for example, 100 steps per minute or $3000-3500$ steps in 30 minutes (1000 steps $x 3$ in 10 minutes). The goal of 100 steps per minute is important for moderate activity, but it may not be a realistic goal for sedentary or elderly individuals, or individuals with disabilities, and chronic diseases. In this regard, while making recommendations about the number of steps, the general approach is acting with the idea of "better than nothing" or "better than ever" and putting reachable goals for individuals is necessary. This review is designed to give detailed information on sedentary behavior, the number of steps, and health.
\end{abstract}

Key words: Number of step, health, sedentary behavior, walking.

öz

Uzun süreli sedanter veya hareketsiz yaşam sağlıklı ve kaliteli bir yaşamı negatif olarak etkileyen risk faktörlerinin başında gelmektedir. Tüm dünyada halk sağlığı kampanyalarında, sedanter yaşamı önlemek için fiziksel aktivite (FA) önerileri yapılmaktadır. Bu önerilerin başında günlük yaşam ve serbest zamanda yapılabilen, herhangi bir malzeme ya da ekipman gerektirmeyen, maliyeti olmayan ve herkesin kolayca yapabileceği "yürüyüş" aktivitesi yer almaktadır. Yetişkinler için günde 10000 adım atılması önerilmektedir fakat 10000 adım hedefine tek bir aktivite süresinde ulaşmak zordur. Bu nedenle, FA rehberlerindeki öneriler ile uyumlu olarak, bir dakikada 100 adım; 30 dakikada 3000-3500 adım (10 dakikada 1000 adım x 3) atılarak orta şiddette bir aktivite planı uygulanabilir. Orta şiddetli bir aktivite için dakikada $100 \mathrm{adım}$ vurgusu önemlidir fakat sedanter, yaşlı, engelli veya kronik hastalığı olan bireyler için gerçekçi bir hedef olmayabilir. Bu doğrultuda, adım sayısı ile ilgili tavsiyelerde bulunurken, genel yaklaşım "hiçbir şey yapılmamasından daha iyidir" veya "her zamankinden daha iyi" düşüncesiyle hareket edilerek ulaşılabilir hedefler konulmalıdır. $\mathrm{Bu}$ derleme sedanter yaşam, adım sayısı ve sağlık konusunda detaylı bilgi vermek üzere hazırlanmıştır.

Anahtar sözcükler: Adım sayısı, sağlık, sedanter davranış, yürüyüş. 
Available at: http://journalofsportsmedicine.org and http://dx.doi.org/10.5152/tjsm.2019.118

Cite this article as: Can S. Sedentary behavior, number of steps and health. Turk J Sports Med. 2019;54(1):71-82.

\section{GíRIŞ}

Fiziksel aktivitenin (FA) en popüler ve yaygın tanımı; "İskelet kaslarının kasılması sonucu ortaya çıkan enerji harcanmasıyla sonuçlanan bedensel hareketlerdir" (1). Düşük yoğunluklu fiziksel aktiviteler, günlük enerji harcamasının önemli bir belirleyicisidir, fakat çevresel, sosyal ve iş yaşamı değişiklikleri ile birlikte günlük aktivitelerin büyük bir kısmı sedanter olarak harcanan zamanın artmasına neden olmaktadır $(2,3)$. Çoğu yetişkin birey ev, işyeri ve ulaşım başta olmak üzere serbest zamanının çoğunu oturarak geçirmektedir. Artan teknolojik gelişmeler, yapılan mesleki işlerin daha az FA ve daha fazla zihinsel aktiviteyle yapılmasına ve yaşamın her alanında daha uzun süre ekran başında zaman geçirilmesine neden olmaktadır. Yetişkin bireylerin bir iş gününün yaklaşık üçte birini oturarak geçirdikleri, aynı zamanda serbest zamanlarının çoğunu da sedanter geçirerek herhangi bir FA yapmadıkları belirtilmektedir $(4,5)$. Buna karşın, günde 7 saat oturan ve 2 saat televizyon izleyen bir ofis çalışanı, düzenli FA veya egzersiz programına katıldığında hem "fiziksel olarak aktif" olabilmekte hem de "sedanter" faaliyetleri gerçekleștirebilmektedir $\quad(2,3)$. Günlük yaşantımızın çoğunu oluşturan sedanter yaşam tarzı ve düşük enerji harcaması gerektiren fiziksel aktiviteler, başta kalp-damar, metabolik, kas-iskelet sistemi hastalıkları ve kanser olmak üzere, bulaşıcı olmayan hastalıklar için risk faktörüdür ve erken mortaliteye neden olmaktadır (6). Bu doğrultuda bu derlemede, "adım sayısı", "pedometre", "sedanter davranış", "fiziksel aktivite" ve "sağllk" terimleri kullanılarak "PubMed", "SportDiscus" ve "Google Scholar"da tarama yapilmış ve sedanter davranış, adım sayısı ve sağlı ilişkisi hakkında detaylı bilgi verilmiştir.

\section{Sedanter Davranış ve Fiziksel İnaktivite}

Sedanter Davranış (SD) kelimesi için farklı tanımlamalar yapılmıştır. Latince kökenli "sedere" kelimesi, "oturma" anlamına gelmektedir (7). SD dinlenme seviyesinin üzerinde enerji harcanan, ancak enerji harcamasında artış oluşturmayan uzanma, yatma, oturma, televizyon izleme, bilgisayar kullanma gibi pozisyonları içeren aktivitelerdir (8). Başka bir tanıma göre; 1.5 MET'den (Metabolic Equivalent of Task) düşük enerji harcaması gerektiren aktivitelerdir. Bu tanımın zayıf yönü "pozisyon ve duruş" içeren hareketleri içermemesidir (7). Genel olarak uyku SD'nin bir parçası olarak görülmemekte, postürün tanımlara dahil edilip edilmemesi konusunda ise ortak bir görüş bulunmamaktadır $(7,9)$. SD tanımının adım sayısına göre belirlenmesi konusunda önemli araştırmaları bulunan Tudor-Locke ve ark. (10), günde 5000'den az adım atan bireyleri "sedanter" olarak tanımlamaktadır. Spor ve egzersiz literatüründe ise "sedanter" terimi genellikle orta-şiddetli fiziksel aktivitenin yokluğunu tanımlamak için kullanılmakta, önerilen düzeyde fiziksel aktivite yapmayan bir birey "sedanter" olarak tanımlanmaktadır (11). SD için farklı tanımlamalar yapılmasının sedanter davranışı ölçmeyi zorlaştırdığı ve "sedanter davranışın sağlık üzerine etkileri" sorusuna net olarak cevap verilememesine neden olduğu belirtilmiştir (7). Bu doğrultuda "Sedentary Behaviour Research Network" ekibi literatürdeki farklı tanımlamalara vurgu yapmış ve SD'nin oturma veya yatma pozisyonunda 1.5 MET'den az enerji harcaması ile karakterize "uyanık durumdaki davranış" olarak tanımlanması gerektiğini vurgulamıştır (12). Fiziksel inaktivite ise sedanter davranıştan farklıdır. FA rehberlerine göre yeterli miktarda aktivite yapmayan birey fiziksel olarak inaktif olarak tanımlanmaktadır (12). Düşük yoğunluklu FA ise, genellikle SD olarak ifade edilmektedir, fakat enerji harcamasının 1.6-2.9 MET arasında olması SD'den ayıran yönüdür (örneğin, yavaş yürüyüş, yazı yazmak, yemek pişirmek gibi) $(2,6,13)$. Orta-şiddetli fiziksel aktiviteler ise, tempolu yürüyüş veya koşu gibi 
en az 3 MET ve üstü aktiviteler olarak tanımlanmaktadır (6). Dünya Sağlık Örgütü'ne (DSÖ) göre dünyada yetişkin nüfusun $1 / 4$ 'i fiziksel olarak inaktifdir ve bu durum birçok risk faktörüne neden olmaktadır (14). Ek olarak, adölesan popülasyonun yaklaşık \%80'inin yeterince aktif olmadığı, kişi bașı yıllık maliyeti ülkeden ülkeye değișmekle birlikte, inaktivitenin 28-418 dolar sağlık harcamasına neden olduğu belirtilmiştir. DSÖ'ye üye 194 devletin \%56'sı fiziksel inaktiviteyi ele alan politikalar geliştirmiş ve 2025 yılına kadar fiziksel inaktiviteyi \%10 azaltmayı hedeflemiştir (14). Bu politikalar arasında, düzenli yapılan FA'nın öneminden dolayı birçok ülkenin kendi toplumuna özgü FA rehberleri hazırladı̆̆ görülmektedir. İnaktiviteyi azaltmak, sağlı̆̆ korumak ve geliştirmek için ilk FA önerileri Amerikan Spor Hekimliği Koleji (ACSM) tarafından yapılmıştır. Ardından, 1995 yılında Hastalıkları Kontrol ve Önleme Merkezi (CDC), ACSM ve 1996'da US (Surgeon General's Report) fiziksel aktivite raporu yayınlayarak bu konudaki çalışmalara yön vermiştir (15). Fakat farklı kuruluşlar farklı FA önerilerinde bulunmuşlardır. 2008 yılında Amerikan Kalp Birliği (AHA) ve ACSM FA önerilerine açıklık getirmiş (15), Kanada, İngiltere, İrlanda, Avusturya, Finlandiya, İsveç, Çin ve Türkiye dahil birçok ülke kendi ulusal FA rehberlerini hazırlamıştır. Dünya genelinde FA rehberleri aktivitenin sıklığl, süresi ve şiddeti üzerine vurgu yaparak "Ne kadar fiziksel aktivite?" sorusuna yanıt aramakta, yapılan öneriler benzerlik göstermektedir $(10,16)$. Bu rehberler ıșığında, DSÖ (17) 18-64 yaş arası yetişkinler için, haftada en az 150 dakika (dk) orta şiddette ( $30 \mathrm{dk}$ x 5 gün) veya haftada en az $75 \mathrm{dk}$ şiddetli aerobik egzersiz önermekte ve aktivite süresinin bir kerede en az $10 \mathrm{dk}$ olması gerektiğini vurgulamaktadır. Beș ile on yedi yaș arasındaki bireyler için ise günde en az $60 \mathrm{dk}$ orta-şiddetli aktivite yapılması önerilmektedir. Aerobik aktivitelere ek olarak, haftanın en az 2-3 gününde büyük kas gruplarını içeren kuvvet egzersizlerinin, denge ve koordinasyonu içeren nöromotor aktivitelerin yapılması gerektiği belirtilmektedir. Bu önerileri yaparken, bireyin FA alışkanlıkları ile uyumlu ve sevdiği bir aktivitenin tercih edilmesi önemlidir. Ayrıca ulaşılması istenen hedef, fiziksel uygunluk düzeyi ve sağlık durumu gözönüne alınarak belirlenmelidir. Bununla birlikte, ACSM (18) inaktivitenin azaltılması, sağlığın geliştirilmesi ve korunması için "Egzersiz ilaçtır" sloganını 2007 yılında kullanmaya başlamıştır. Ülkemizde de ACSM öncülüğünde "Egzersiz İlaçtır Türkiye" programı, FA ve egzersiz önerilerini yaşam tarzı haline getirmek için yürütülen bir programdır. Programın amacl, birinci basamak sağlık hizmeti sunmakla görevli hekimlerin ve sağlık hizmeti sağlayanların hastalıkların önlenmesi ve tedavisinde düzenli fiziksel aktiviteyi de dahil etmelerini, hekimlerin de egzersiz reçetelemesi yapmasını teşvik etmektir (19). Son 10 yllda FA rehberlerine ek olarak, Japonya, Avustralya, Kuzey İrlanda, ABD başta olmak üzere birçok ülke ve WHO, ACSM, CDC gibi kuruluşlar "Fiziksel aktivitenin özendirilmesi" ve "Obezite ile mücadele" gibi halk sağlığı kampanyalarında motive edici pedometre kullanımını teşvik ederek adım sayısının önemine vurgu yapmışlardır $(15,20)$. Ülkemizde de 2013 yılında, "Obezite ile Mücadele" kapsamında sağlıklı bireyler için 10000 adım/gün önerisi ile sağlıklı ve kaliteli yaşam kampanyası başlatılmıştır.

\section{Günde Kaç Adım?}

10000 adım/gün kavramı, Japonya'da bulunan bir pedometre üreticisinin (Yamasa Corporation, Tokyo, Japonya) 1960'lardaki sloganına dayanmaktadır. Yetişkin bireyleri sağlıklı yaşama teşvik etmek için kamu sağlığı mesajı olarak 10000 adımın önemine değinilmiştir. Kanada, pedometre ile adım sayısı takibi programını uygulayan ilk ülke olmuş ve bu yaklaşımın FA'yı artırmada önemli gelişmeler sağladığı vurgulanmıștır (21). Günümüzde de fiziksel aktiviteyi ölçmek ve teşvik etmek için, teknolojinin getirmiş olduğu yenilikler ile akıllı telefonlardan yararlanılabilmektedir. Akıllı telefonlarda adım sayısını gösteren programların bulunması, "adım sayısı" kavramının popüler olduğunu göstermektedir. Fakat FA rehberlerinde genellikle adım sayısı ile ilgili tutarsız bilgilerin olduğu, önerilerin FA rehberleri ile uyumlu hale getirilmesi gerektiği 
belirtilmiştir (15). Bugüne kadar yapılan araştırmalarda yaş, eğitim seviyesi, cinsiyet, medeni durum, meslek, mevsim ve kronik hastalık varlığ gibi birçok duruma göre değişmekle birlikte, yetişkin bireylerde adım sayısının 4000-18000 adım/gün arasında değiştiği belirtilmiştir (10). Bireyler arası farklılıklar olmasına rağmen, "az da olsa fiziksel aktivite yapılması hiçbir şey yapılmamasından daha iyidir" bakışı doğrultusunda araştırmacılar, orta şiddetli FA ile ilgili adım sayısı önerilerinde bulunmanın sağlıklı, kaliteli bir yaşam için önemli olduğunu, özellikle spor geçmişi olmayan, uzun süre sedanter yaşayan bireyler için güvenli olduğunu belirtmektedir (10). Ayrıca, yürüyüș hem günlük hem de serbest zaman aktivitesi olarak tercih edildiğinden, özellikle FA seviyesini artırmak için adım sayısı motivasyonel bir öneri olarak kullanılmaktadır (15). 10.000 adım, adım uzunluğuna göre değişmekle birlikte yaklaşık 8 kilometre olup, vücut ölçülerine ve egzersiz şiddetine bağlı olarak ortalama 300-400 kalori harcamaya eșdeğerdir. Fakat sürekli adım saymaya odaklanmanın, obsesif bir davranışa ve aktivite programlarının bırakılmasına neden olabileceği de göz önünde bulundurulmalıdır (22). Tudor Locke ark. (21) göre, günde 5000 adımdan az atanlar "sedanter", 5000-7499 adım atanlar "düşük aktif", 7500-9999 adım atanlar "biraz aktif", 10000-12499 adım atanlar "aktif", 12500 adımdan fazla atanlar "yüksek aktif" kategorisine girmektedir. "Sedanter" kategorisi 2008 yllında yeniden revize edilmiş, günde 2500 adımdan az "bazal aktivite", 2500-4999 adım "sınırlı aktivite" olarak iki bölüme ayrılmıştır (23). Çoğu yetişkin düzenli günlük aktivitelerinde 4000-6000 adım atmaktadır. Orta-şiddetli diğer aktivitelerden kazanılması gereken ek adım sayısı ise 3000-6000 arasındadır (22). Yürüyüş miktarını ölçen pedometrelerin ve akselerometrelerin en büyük dezavantajı egzersizin şiddetini ve süresini belirleyememesidir (15). Bu nedenle adım sayısı şiddetini belirlemek için 1 dakikada atılan adım sayısının orta şiddetteki egzersiz için bir kriter olabileceği belirtilmiştir. Tudor-Locke ve ark. (24), genç, sağlıklı bireylerde orta şiddette egzersiz için atılması gereken adım sayısının erkeklerde 96 adım/dk, kadınlarda 107 adım/dk, her iki cinsiyet için ortalama 100 adım/dk olduğunu; Beets ve ark. (25), 106 adım/dk'nın 3.2 MET, onun da yaklaşık 4.5 $\mathrm{km} / \mathrm{saat}$ hızla yürümeye; Abel ve ark. (26) ise $114 \mathrm{adım} / \mathrm{dk}^{\prime}$ ın $4.0 \mathrm{MET}$ ve $4.80 \mathrm{~km} / \mathrm{saat}$ hıza karşılık geldiğini belirtmiştir. Beş ayrı çalışmada ise (24-28), orta şiddette egzersiz için 3000 adım/30 dk veya $100 \mathrm{adım} / \mathrm{dk}^{\prime}$ nın 3 MET değerinde olduğu vurgusunun önemli olduğu, mevcut FA önerileri ile tutarlı olması için ise fiziksel aktivitenin 5 gün/hafta, yaklaşık 3000$4000 \mathrm{adım} / 30 \mathrm{dk}$ (1000 adım/10 dk x 3) olması gerektiği belirtilmiştir $(24,27)$. Bununla birlikte Pal ve ark. (29) ise 30 dk'llk yürüyüșün 30003500 adıma karşılık gelebileceğini vurgulamışlardır. Ayrıca günlük orta şiddetli FA için ise 7100-11000 adımı tamamlayabilmenin önemli olduğu; FA rehberleri ile uyumluluk için ise orta şiddetli bir aktivitenin en az 7000-8000 adıma karşılık geldiği, sağlıklı yaşlı bireylerde rutin günlük aktivitelere ek olarak günlük toplam 30 dakikalık orta-şiddetli FA'nın yaklaşık 7000-10000 adıma eş değer olduğu belirtilmiştir (30). Halk sağlığı önerisi olarak bazı FA rehberleri, günde $60 \mathrm{dk}$ orta şiddetli egzersiz önermektedir. $\mathrm{Bu}, 100 \mathrm{adım} / \mathrm{dk}$ veya 6000 adım anlamina gelmektedir ve sedanter düzeye (5000 adım) ek olarak toplam 11000 adıma eş değerdir. Fakat inaktif bireylerin 10000-12000 adım sayısına ulaşmaları daha zor olacağından, bireye göre önerilerin yapılması gerekmektedir (10). $100 \mathrm{adım} / \mathrm{dk}$ prensibi ve günlük en az 5000 adım önerisi; yaşlılar, özel popülasyonlar veya bazı kronik hastalığı olanlar için gerçekçi olmayabileceğinden, egzersizler 10 'ar dakikalık bölümler şeklinde yapılmalıdır (30). Miller ve Brown (31), çalışan yetişkinlerde haftada en az $150 \mathrm{dk}$ egzersiz yapanların günde ortalama 9500 adım attıklarını; Behrens ve ark. (32), 7 gün süre ile pedometre ve akselerometre takan öğrenciler ile yapılan çalışmalarında en az $30 \mathrm{dk}$ orta şiddette egzersizin ortalama 11800 adım/gün eşdeğeri olduğunu belirtmişlerdir. 2005-2006 Amerika Birleşik Devletleri popülasyonunda yapılan Ulusal Sağlık ve Beslenme Araştırması'nda (NHANES) ise, 3500 bireyin 7 gün süre ile attıkları adım sayıları incelenmiştir. Araştırma sonucunda her iki 
cinsiyet için günde ortalama $30 \mathrm{dk}$ aktivitenin 8000 adıma karşılık geldiği; haftada $150 \mathrm{dk}$ orta şiddette egzersizin ise yaklaşık 7000 adıma (49000 adım/hafta) eşdeğer olduğu belirtilmiştir (10).

Buna ek olarak, erkek çocukların ortalama 12000-16000 adım/gün, kız çocukların ortalama 10000-13000 adım/gün, adölesanların ise ortalama 8000-9000 adım/gün attıkları görülmüștür. FA rehberleri ile uyumlu olarak orta şiddetli aktivite için 3300-3500 adım/30 dk veya $6600-7000 \mathrm{adım} / 60 \mathrm{dk}$ atılması gerektiği belirtilmiștir $(33,34)$.

\section{Adım Sayısını Etkileyen Faktörler}

Adım sayısını etkileyen faktörler içinde yaş, cinsiyet, vücut ağırlığl, eğitim düzeyi, gelir düzeyi, meslek, çalışma şekli (tam gün, vardiya vb), sigara kullanımı, kronik hastalıklar, fiziksel engellilik, mevsim, kültür ve irk (Afro Amerikalı vb.) bulunmaktadır (35-39). Dasgupta ve ark. (40), diyabetik bireylerde adım sayısının kış mevsiminde 5000'den az olduğunu; benzer şekilde Yasunaga ve ark. (41), 65-83 yaş aralığındaki bireylerde kış aylarında 5000 adım/gün'den daha düşük olduğunu; Mitsui ve ark. (42), erkek ofis çalışanlarında çalıșılmayan günlerde adım sayısının kış mevsiminde yaz mevsimine göre daha az olduğunu belirtmişlerdir. Mantovani ve ark. (39) hafta içi günlerde hafta sonuna göre daha inaktif olunduğunu, erken yaşta spora başlayan yetişkinlerden oluşan grupta fiziksel inaktivite prevelansının daha düşük olduğunu ve bu grupta günde 7500'den fazla adım atma oranının daha fazla olduğunu bildirmişlerdir. Yapılan çalışmalarda $(43,44), 50$ yaşından sonra aktivite düzeyinin düștüğü belirtilmiştir. Sisson ve ark. (45), ABD'de günde 5000 adım atan bireylerin daha yaşli, düşük gelir düzeyine sahip kadınlar olduklarını belirtmiştir. Dwyer ve ark. (46), yaş ortalaması 50 olan 592 kişiyi 5 yıl süreyle izlemişler, katılımcıların \%65'inde yaş arttıkça adım sayısının azaldığını bulmuşlardır. Bohannon (47), 65 yaş üstündeki bireylerin adım sayılarının, 65 yaș altındaki bireylere göre daha az olduğunu bildirmiştir. Özellikle yaşlı ve kronik hastalığı olan bireyler, önerilen 10000 adım/gün önerisine uyum sağlayamadıklarından, bu bireylere gerçekçi önerilerde bulunulması gerektiğini belirtmiștir. Bununla birlikte, 10000 adım programını sürdürmenin zorluğu, aktivite programlarını sürdürmek için egzersiz kapsamının kademeli artırılması ve partner ile (arkadaş, eş ile yürüyüș gibi) egzersiz yapmanın önemi vurgulanmaktadır. Farklı ülke ve popülasyonlara yönelik adım sayısı verileri Tablo 1'de verilmiștir.

Tablo 1. Farklı popülasyonlardaki bireylerin günlük adım sayıları

\begin{tabular}{|c|c|c|c|c|}
\hline Yazar & Örneklem & Yöntem & \multicolumn{2}{|c|}{ Özet Bulgular } \\
\hline $\begin{array}{l}\text { Schmidt ve ark. } \\
\text { (48) } \\
\text { Avustralya }\end{array}$ & $\begin{array}{l}\mathrm{n}: 1793 \\
26-36 \text { yaș }\end{array}$ & $\begin{array}{l}\text { Yamax Digi-Walker } \\
\text { SW200 } \\
7 \text { gün }\end{array}$ & $\begin{array}{l}\text { Erkek } \\
\% 7.8 ; 0-4999 \\
\% 27.9 ; 5000-7499 \\
\% 27.3 ; 7500-9999 \\
\% 21.4 ; 10000-12999 \\
\% 15.7 ; 12500+\end{array}$ & $\begin{array}{l}\text { Kadın } \\
\% 6.2 ; 0-4999 \\
\% 27.9 ; 5000-7499 \\
\% 33.2 ; 7500-9999 \\
\% 21.3 ; 10000-12999 \\
\% 11.4 ; 12500+\end{array}$ \\
\hline $\begin{array}{l}\text { Clemes ve ark. } \\
\text { (49) } \\
\text { İngiltere }\end{array}$ & $\begin{array}{l}n: 99 \\
18-65 \text { yaș }\end{array}$ & $\begin{array}{l}\text { SW-200 } \\
\text { (New Lifestyles) } \\
4 \text { hafta } \\
\text { (Yaz ve kış mevsimi) }\end{array}$ & $\begin{array}{l}\text { Normal kilolu } \\
\% 60 \geq 10000 \text { (Yaz) } \\
\% 36 \geq 10000 \text { (Kış) } \\
\text { En inaktif gün: Pazar }\end{array}$ & $\begin{array}{l}\text { Fazla kilolu } \\
\% 43 \geq 10000 \text { (Yaz) } \\
\% 35 \geq 10000 \text { (Kış) } \\
\text { En inaktif gün: Pazar }\end{array}$ \\
\hline $\begin{array}{l}\text { Can ve ark. } \\
\text { (50) } \\
\text { Türkiye }\end{array}$ & $\begin{array}{l}\mathrm{n}: 58 \\
\text { Kadın: } 38 \\
\text { Erkek: } 20 \\
\text { Ortyaş: } 32.50 \pm \\
8.82\end{array}$ & $\begin{array}{l}\text { SWA } \\
\text { (BodyMedia, USA) } \\
7 \text { gün }\end{array}$ & $\begin{array}{l}\text { Kadın: } 9479 \pm 3468 \\
\text { Erkek: } 11338 \pm 3297 \\
\text { Hafta içi: } \\
\text { Kadın: } 10067 \pm 3925 \\
\text { Erkek: } 12511 \pm 4530\end{array}$ & $\begin{array}{l}\text { Cumartesi } \\
\text { Kadın: } 9178 \pm 4812 \\
\text { Erkek: } 9415 \pm 6077 \\
\text { Pazar } \\
\text { Kadın: } 7022 \pm 4158 \\
\text { Erkek: } 9208 \pm 4045\end{array}$ \\
\hline Hirvensalo ve & n: 1853 & Omron & $7499 \pm 2908$ & Tam gün: $7450 \pm 2723$ \\
\hline
\end{tabular}




\begin{tabular}{|c|c|c|c|c|}
\hline Yazar & Örneklem & Yöntem & Özet & lgular \\
\hline $\begin{array}{l}\text { ark. } \\
\text { (51) } \\
\text { Finlandiya }\end{array}$ & $30-45$ yaș & $\begin{array}{l}\text { (HJ-152R-E) } \\
7 \text { gün }\end{array}$ & $\begin{array}{l}\text { Kadın: } 7824 \pm 2925 \\
\text { Erkek: } 7089 \pm 2774 \\
\text { Hafta içi: } 7712 \pm 3071 \\
\text { Hafta sonu: } 7048 \pm 359\end{array}$ & $\begin{array}{l}\text { Vardiya: } 7715 \pm 3136 \\
\text { Kadın: } \% 20 \geq 10000 \\
\text { Erkek: } \% 15 \geq 10000\end{array}$ \\
\hline $\begin{array}{l}\text { Tudor-Locke } \\
\text { ve ark. (52) } \\
\text { ABD }\end{array}$ & $\begin{array}{l}\text { n: } 3744 \\
\text { Erkek: } 1781 \\
\text { Kadın: } 1963 \\
20 \text { - } 85 \text { yaş }\end{array}$ & $\begin{array}{l}\text { ActiGraph } \\
\text { AM-7164 } \\
7 \text { gün }\end{array}$ & $\begin{array}{l}\text { Erkek } \\
\% 14.1 ;<2500 \\
\% 20.6 ; 2500-4999 \\
\% 24.2 ; 5000-7499 \\
\% 19.3 ; 7500-9999 \\
\% 10.9 ; 10000-12499 \\
\% 10.8 ; 12500+\end{array}$ & $\begin{array}{l}\text { Kadın } \\
\% 19.9 ;<2500 \\
\% 30.0 ; 2500-4999 \\
\% 28.8 ; 5000-7499 \\
\% 13.2 ; 7500-9999 \\
\% 4.8 ; 10000-12499 \\
\% 3.3 ; 12500+\end{array}$ \\
\hline $\begin{array}{l}\text { Fukuoka ve } \\
\text { ark. (53) } \\
\text { Japonya }\end{array}$ & $\begin{array}{l}\text { n: } 63 \\
\text { Kadın: } 32 \\
\text { Erkek: } 31 \\
19-69 \text { yaș }\end{array}$ & $\begin{array}{l}\text { Omron HJ-3 } \\
7 \text { gün }\end{array}$ & $\begin{array}{l}\text { Kadın } \\
\text { 19-29: } 8526 \pm 2915 \\
\text { 30-39: } 10763 \pm 925 \\
\text { 40-49: } 13207 \pm 4037 \\
\text { 50-59: } 9639 \pm 4012 \\
60-69: 11415 \pm 5452\end{array}$ & $\begin{array}{l}\text { Erkek } \\
\text { 19-29: } 11110 \pm 2765 \\
\text { 30-39: } 7530 \pm 2380 \\
\text { 40-49: } 8759 \pm 2001 \\
\text { 50-59: } 7072 \pm 3913 \\
\text { 60-69: } 9312 \pm 1907\end{array}$ \\
\hline $\begin{array}{l}\text { Demirci (54) } \\
\text { Türkiye }\end{array}$ & $\begin{array}{l}\text { n: } 80 \\
\text { Kız: } 39 \\
\text { Erkek: } 41 \\
11-13 \text { yaş }\end{array}$ & $\begin{array}{l}\text { ActiGraph } \\
\text { wGT3X-BT } \\
7 \text { gün }\end{array}$ & $\begin{array}{l}\text { Kız: } 13242 \pm 2652 \\
\text { Erkek: } 15762 \pm 2997 \\
\text { Okul içi: } 6585 \pm 1707 \\
\text { Okul dışı: } 8662 \pm 2375\end{array}$ & $\begin{array}{l}\text { Hafta içi: } \\
\text { Kız: } 13760 \pm 2687 \\
\text { Erkek: } 16580 \pm 3548 \\
\text { Hafta sonu: } \\
\text { Kız: } 12035 \pm 4231 \\
\text { Erkek: } 13406 \pm 3056\end{array}$ \\
\hline $\begin{array}{l}\text { Burns ve ark. } \\
\text { (55) } \\
\text { Kafkas, } \\
\text { Hispanik, Afro } \\
\text { Amerikan, } \\
\text { Kızlderili, } \\
\text { Asya, Pasifik } \\
\text { Adalı }\end{array}$ & $\begin{array}{l}\text { n: } 1714 \\
\text { Kız: } 926 \\
\text { Erkek: } 788 \\
\text { Ort }_{\text {yaş: } 9.7 \pm 1.0}\end{array}$ & $\begin{array}{l}\text { Yamax } \\
\text { Digi-Walker SW200 } \\
7 \text { gün }\end{array}$ & $\begin{array}{l}\text { Kız: } 10218 \pm 3195 \\
\text { Erkek: } 12088 \pm 3895\end{array}$ & $\begin{array}{l}\text { Sinıf: } \\
\text { Kız: } 1850 \pm 1390 \\
\text { Erkek: } 2261 \pm 1707 \\
\text { Okul içi: } \\
\text { Kız: } 5242 \pm 1712 \\
\text { Erkek: } 6018 \pm 1915\end{array}$ \\
\hline $\begin{array}{l}\text { Tudor-Locke } \\
\text { ve ark. (56) } \\
\text { Avustralya, } \\
\text { Kanada, } \\
\text { Fransa, İsviçre, } \\
\text { ABD }\end{array}$ & $\begin{array}{l}\text { n: } 3127 \text { birey } \\
\text { Erkek: } 976 \\
\text { Ortyas: } 46.8 \pm 15.4 \\
\text { Kadın: } 2151 \\
\text { Ortyas: } 47.4 \pm 14.9 \\
18-94 \text { yaş }\end{array}$ & $\begin{array}{l}\text { Yamax (Yamax } \\
\text { Corporation, Tokyo, } \\
\text { Japan) }\end{array}$ & $\begin{array}{l}\text { Normal kilolu } \\
\text { Erkek } \\
\text { 18-50.9: } 10084 \pm 3503 \\
\text { 51-88: } 8938 \pm 3451 \\
\text { Kadın } \\
\text { 18-39.9: } 9399 \pm 3348 \\
\text { 40-49.9: } 8726 \pm 3124 \\
\text { 50-59.9: } 8289 \pm 3670 \\
\text { 60-94: } 7021 \pm 3362\end{array}$ & $\begin{array}{l}\text { Fazla kilolu } \\
\text { Erkek } \\
\text { 18-50.9: } 8802 \pm 3709 \\
\text { 51-88: } 6924 \pm 3318 \\
\text { Kadın } \\
\text { 18-39.9: } 7562 \pm 3453 \\
\text { 40-49.9: } 7177 \pm 3000 \\
\text { 50-59.9: } 6580 \pm 3324 \\
\text { 60-94: } 5362 \pm 2801\end{array}$ \\
\hline $\begin{array}{l}\text { Mantovani ve } \\
\text { ark. (39) } \\
\text { Brezilya }\end{array}$ & $\begin{array}{l}\mathrm{n}: 278 \\
\text { Ort }_{\text {yaş: }} \\
46.51 \pm 9.02\end{array}$ & $\begin{array}{l}\text { Yamax } \\
\text { Digi-Walker SW200 } \\
7 \text { gün }\end{array}$ & $\begin{array}{l}\% 12.9 ; \geq 10000 \\
\% 30.9 ; \geq 7500\end{array}$ & \\
\hline $\begin{array}{l}\text { Can ve ark. } \\
\text { (57) } \\
\text { Türkiye }\end{array}$ & 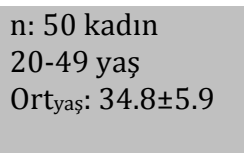 & $\begin{array}{l}\text { SWA } \\
\text { (BodyMedia, USA) } \\
7 \text { gün }\end{array}$ & $\begin{array}{l}10941 \pm 2236 \\
20-29: 11650 \pm 2521 \\
30-39: 10818 \pm 2359 \\
\text { 40-49: } 10367 \pm 1576\end{array}$ & \\
\hline $\begin{array}{l}\text { Can ve ark. } \\
\text { (58) } \\
\text { Türkiye }\end{array}$ & $\begin{array}{l}\text { n: } 111 \text { kadın } \\
\text { 20-49 yaş }\end{array}$ & $\begin{array}{l}\text { SWA } \\
\text { (BodyMedia, USA) } \\
7 \text { gün }\end{array}$ & $\begin{array}{l}9867 \pm 1756 \\
\% 45 ; \geq 10000\end{array}$ & \\
\hline
\end{tabular}

\section{Kronik Hastalıklar ve Adım Sayısı}

Yaşlı ve kronik hastalığı olan bireylerde günlük adım sayısının az olduğuna yönelik güçlü kanıtlar vardır. Yaşlı bireylerde adım sayısının günde 2000-9000, özel popülasyondaki bireylerde 1200-8800 adım olduğu belirtilmiştir (30). Kardiovasküler, KOAH, son dönem böbrek yetmezliği, artrit, fibromiyalji gibi kronik hastalıklar, kardiometabolik risk faktörü ve metabolik sendromu yada fiziksel engeli olan 
bireylerin ortalama adım sayıları günde 35005500 olarak rapor edilmiștir (23). DePew ve ark. (59) KOAH hastalarında ortalama adım sayısının günde 3826, Moy ve ark. (60) 5680, Van Sloten ve ark. (61) hareket sinırlılı̆̆ı olmayan diyabetiklerde ortalama 6429, Naal ve Impellizzeri (62) eklem problemi olan bireylerde 6721 adım olduğunu belirtmiștir. Adım sayısının, engelli yaşlı bireylerde 1214 ile en düşük düzeyde olduğu, KOAH'lı hastalarda günde 2237, Tip 2 DM'lilerde 6291, Tip 1 DM'lilerde 8000, zihinsel engellilerde 7787 ve HIV pozitif bireylerde 7545, meme kanseri teşhisi konanlarda 7409, diyaliz tedavisi alanlarda 3448 (23), morbid obez bireylerde ise ortalama 5000 adımdan düşük olduğu gösterilmiştir (63-65).

\section{Adım Sayısı ve Sağlık}

ACSM günde 10000 adım atmanın kardiorespiratuvar sağlığı geliștirdiğini, obezite, prediyabet ve Tip 2 DM gibi birçok kronik hastalığın önlenmesinde ve tedavisinde önemli olduğunu vurgulamaktadır (10). McKercher ve ark. (66), günde 7500 adımdan fazla atan kadınlarda 5000 adımdan az atanlara göre depresyon görülme oranının daha az olduğunu, günde 12500 adımdan fazla atan erkeklerin 5000 adımdan az atanlara göre depresyon prevelansinda $\% 50$ azalma olduğunu belirtmişler, fakat sadece kadınlarda istatistiksel olarak anlamlı fark bulmuşlardır. Krumm ve ark. (67) post menopozal kadınlarda 14 gün süre ile pedometre kullanarak yaptıkları araştırmada vücut kompozisyonu ve adım sayısı arasındaki ilişkiyi incelemişlerdir. Araştırmacılar, günde 5000-7500 adım atan kadınlarda 5000 adımdan az atanlara göre beden kütle indeksi (BKİ) ve bel çevresinin daha düşük, 7500-9999 adım atanların BKİ ve bel çevresi değerlerinin 50007500 adım atanlara göre anlamlı olarak daha düşük, 7500-9999 adım atanlar ile 10000 adımdan fazla atanlar arasında ise anlaml farklılık olmadığını belirtmişlerdir. Schmidt ve ark. (48) günde 5000 adımdan az atan bireylerin kardiyometabolik risk faktörlerine sahip olma prevelansının fazla olduğunu rapor etmişlerdir. Bravata ve ark. (20) pedometre kullanımının motivasyonu artırarak FA yapma oranını \%27 artırdığını, BKİ ve kan basıncında azalma sağladığını, fakat bu değişikliklerin uzun süreli korunup korunmaması ile ilgili kesin verilerin olmadığını bildirmișlerdir. Freak-Poli ve ark. (68) işyeri çalışanlarında 4 ay süreyle pedometre kullanımı uygulamışlar, fiziksel olarak daha aktif olup daha geniş bel çevresine sahip bireylerin bel çevrelerinde belirgin azalma olduğunu vurgulamışlardır. Dwyer ve ark. (46) mevcut adım sayısına ek olarak 1000 adım atmanın BKİ, bel-kalça oranında azalma ve insülin duyarlılığında artma sağladığını belirtmişlerdir. 278 yetişkin bireyin incelendiği diğer bir araştırmada (39) ise günde 7500 adım atanlarda obezite oranının daha az, uyku kalitelerinin kötü; 5000 adımdan az atanların ise uyku kalitelerinin daha da kötü olduğu belirtilmiştir. Van Dyck ve ark. (69) Tip 2 DM’li ve obez hastalarda bazal değerlerin üzerine ek olarak haftada 5 gün, günde 4000 adım atan hastalarda $\mathrm{HbA1c}$ değerlerinde anlamlı iyileşme olduğunu, fakat sonuçların dikkatli yorumlanması gerektiğini belirtmişlerdir. Farklı örneklem gruplarına yönelik yapılan adım sayısı araştırmaları Tablo 2'de verilmiştir.

Tablo 2. Farklı örneklem gruplarında adım sayısı ve sağlı üzerine etkileri

\begin{tabular}{|c|c|c|c|}
\hline Yazar & Örneklem & Yöntem & Özet Bulgular \\
\hline Gray ve ark. (70) & $\begin{array}{l}\mathrm{n}: 48 \\
\text { Erkek sedanter } \\
\text { Ort }_{\text {yaş: } 49 \pm 8.9 \text { yll }} \\
18-65 \text { yaş }\end{array}$ & $\begin{array}{l}\text { Omron HJ-109E } \\
7 \text { gün/12 hafta } \\
\text { Adım sayısı protokolü } \\
5 \text { gün/hafta } \\
\text { Aktivite grubu: } 24 \\
\text { Kontrol grubu: } 24\end{array}$ & $\begin{array}{l}\text { 12. hafta aktivite grubu adım sayısında } \\
\text { anlamlı artış ( } \geq 10000), \\
\text { Glukoz, insülin duyarlılığı ve C-reaktif } \\
\text { protein üzerinde anlamlı herhangi bir } \\
\text { değişiklik görülmemiş. } \\
\text { Gözetim altında olmayan aktivitelerin } \\
\text { yoğunluk ve süresi takip edilememiş. }\end{array}$ \\
\hline
\end{tabular}




\begin{tabular}{|c|c|c|c|}
\hline Mendoza ve ark. (71) & $\begin{array}{l}\text { n: } 102 \\
\text { KOAH } \\
\text { Ort }_{\text {yaş: }} 68.9 \pm 9.5 \text { yll }\end{array}$ & $\begin{array}{l}\text { PD-724 Triaxial } \\
\text { pedometre (Tanita, } \\
\text { Tokyo) } \\
\text { Pedometre ile } 3 \text { ay } \\
\text { bireysel program } \\
\text { Aktivite grubu: } 50 \\
\text { Kontrol grubu: } 47\end{array}$ & $\begin{array}{l}\text { Fiziksel aktivite düzeyi ve yaşam kalitesi } \\
\text { üzerine iyileştirici etki. }\end{array}$ \\
\hline $\begin{array}{l}\text { Araiza } \\
\text { ve ark. (72) }\end{array}$ & $\begin{array}{l}\text { n: } 30 \\
\text { Sedanter } \\
\text { Tip } 2 \text { DM } \\
\text { 33-69 yaş }\end{array}$ & $\begin{array}{l}\text { SW-701 Yamax } \\
\text { Digiwalker } \\
5 \text { gün/hafta } \\
6 \text { hafta } \\
\text { En az } 10000 \text { adım/gün }\end{array}$ & $\begin{array}{l}\text { Fiziksel aktivite düzeylerinde } \% 69 \text { artıș, } \\
\text { HDL ve BMH düzeylerinde artıș, fakat } \\
\text { glisemik kontrol, insülin duyarlılığı ve } \\
\text { kardiovasküler risk parametrelerinde } \\
\text { (Total kolesterol, LDL, TG) anlamlı bir } \\
\text { değișiklik görülmemiș. }\end{array}$ \\
\hline $\begin{array}{l}\text { Schneider ve ark. } \\
\text { (73) }\end{array}$ & $\begin{array}{l}\text { n: } 56 \\
\text { Sedanter } \\
\text { Fazla kilolu ve obez }\end{array}$ & $\begin{array}{l}36 \text { hafta } \\
10000 \mathrm{adım} / \text { gün }\end{array}$ & $\begin{array}{l}\text { Vücut ağırlığı } 2.4 \mathrm{~kg} \text {, BKİ } 0.8 \mathrm{~kg} / \mathrm{m}^{2} \text {, vücut } \\
\text { yağ oranında } \% 1.9 \text {, yağ kütlesinde } 2.7 \mathrm{~kg} \text {, } \\
\text { bel çevresinde } 1.8 \mathrm{~cm} \text { azalma, HDL'de } \\
3 \mathrm{mg} / \mathrm{dl} \text { artış, } \\
\text { Adım sayısının sağlı üzerine etkilerinin } \\
\text { öneminin iyi vurgulanması gerektiği, } \\
10000 \text { adım atmanın tüm yetişkinler için } \\
\text { geçerli olmadığı, Programa bağlı kalanların } \\
\text { vücut kompozisyonlarında daha fazla } \\
\text { iyileşme olduğu görülmüş. }\end{array}$ \\
\hline $\begin{array}{l}\text { Dasgupta ve ark. } \\
\text { (74) }\end{array}$ & $\begin{array}{l}\text { n: } 347 \\
\text { Ortyass: } 60.0 \pm 11.2 \text { yll } \\
\text { \%66 DM ve \%90' } \\
\text { HT }\end{array}$ & $\begin{array}{l}\text { Yamax SW-701 } \\
12 \text { ay } \\
\text { Adım sayısı protokolü } \\
\text { Aktivite grubu: } 174 \\
\text { Kontrol grubu: } 173\end{array}$ & $\begin{array}{l}\text { Adım sayısı protokolünü tamamlayanların } \\
\text { oranı \%79, } \\
\text { Aktivite grubunda adım sayısında } \% 20 \text { 'lik } \\
\text { bir artış, } \\
\text { HbA1c ve HOMA-IR'de azalma. }\end{array}$ \\
\hline Guglani ve ark. (75) & $\begin{array}{l}\text { n: } 102 \\
\text { Tip } 2 \text { DM, Sedanter } \\
40-70 \text { yaș }\end{array}$ & $\begin{array}{l}5 \text { gün/hafta } \\
16 \text { hafta } \\
\text { 1.grup: } 4000 \text { adım/30- } \\
40 \mathrm{dk} / \text { RPE } \\
\text { 2.grup: } 10000 \text { adım } \\
\text { hedefi } \\
\text { 3.grup: Kontrol }\end{array}$ & $\begin{array}{l}\text { Orta şiddette yürüyüş protokolünün } \\
\text { uygulandığı grupta yaşam kalitesinde daha } \\
\text { fazla artış. }\end{array}$ \\
\hline Johnson ve ark. (76) & $\begin{array}{l}\text { n: } 41 \\
\text { Tip2 DM } \\
\text { Ortyaș: } 56.5 \pm 7.2 \text { yıl }\end{array}$ & $\begin{array}{l}\text { Yamax Digi-Walker } \\
\text { SW200 } \\
24 \text { hafta }\end{array}$ & $\begin{array}{l}\text { Vücut ağırlığı, BKİ ve kan basıncında } \\
\text { anlamlı azalma. }\end{array}$ \\
\hline Iwane ve ark. (77) & $\begin{array}{l}\text { n: } 730 \text { Erkek } \\
\text { (550 normo-tansif, } \\
180 \text { HT) } \\
\text { Ort }_{\text {yaş: }} 47.0 \pm 1.0 \text { yıl }\end{array}$ & $\begin{array}{l}12 \text { hafta } \\
4 \text { gün/hafta } \\
\text { Adım sayısı protokolü }\end{array}$ & $\begin{array}{l}\text { 4. haftanın sonunda, } 306 \text { kişinin } 217 \text { 'si } \\
\text { normotansif, } 89 \text { 'u hipertansif, } \\
\text { 12. haftanın sonunda, } \\
\text { Günde } 10000 \text { adımdan fazla atan } 83 \text { bireyin } \\
\text { 51'i normotansif, } 32 \text { 'si hipertansif, } \\
\text { Günde } 10000 \text { adımdan az atan } 223 \text { bireyin } \\
\text { 162'si normotansif, } 57 \text { 'si hipertansif, } \\
\text { Günde } 10000 \text { adımdanfazla atanlarda kan } \\
\text { basıncında ve egzersiz kapasitesinde } \\
\text { iyileșme, } \\
\text { HT hastalarında sempatik sinir } \\
\text { aktivitesinde azalma, } \\
\text { 10000 adım programına uyum } \\
\text { sağlayamayanların oranı } \% 89 \text {. }\end{array}$ \\
\hline De Greef ve ark. (78) & $\begin{array}{l}\text { n: } 20 \\
\text { Tip } 2 \text { DM’li } \\
\text { 35-75 yaş }\end{array}$ & $\begin{array}{l}\text { Yamax Digi-Walker } \\
\text { SW200 } \\
\text { Actigraph, model } 7164 \\
52 \text { hafta } \\
5 \text { gün/12 hafta } \\
\text { Aktivite grubu: } 20\end{array}$ & $\begin{array}{l}\text { Pedometrelerin kısa süreli kullanımı adım } \\
\text { sayısını artırmada, sedanter yaşamı } \\
\text { azaltmada etkili, fakat toplam FA ve uzun } \\
\text { süreli etkileri sınırlı. } \\
\text { İleri sağlık faydaları elde etmek için daha } \\
\text { fazla araștırma yapılması gerekir. }\end{array}$ \\
\hline
\end{tabular}




\begin{tabular}{|c|c|c|c|}
\hline & & Kontrol grubu: 21 & \\
\hline $\begin{array}{l}\text { Kroemeke ve ark. } \\
\text { (79) }\end{array}$ & $\begin{array}{l}\mathrm{n}: 79 \\
\text { Post menopozal } \\
\text { kadın } \\
51-81 \text { yaş } \\
\text { Ortyaş: } 63.25 \pm 5.51 \text { yıl } \text {. }\end{array}$ & $\begin{array}{l}\text { ActiGraph GT1M } \\
7 \text { gün }\end{array}$ & $\begin{array}{l}\text { Günde } 12500 \text { adımdan fazla atanlarda daha } \\
\text { düşük vücut ağırlığı, BKİ ve VYY, } \\
\text { Günde } 10000 \text { adım bu yaş grubu için yeterli } \\
\text { değil. } \\
\text { Sağlığı geliştirmek için post menapozal } \\
\text { dönemdeki kadınlar için en az } 12500 \text { adım } \\
\text { gerekir. }\end{array}$ \\
\hline Pal ve ark. (29) & $\begin{array}{l}\text { n: } 30 \\
\text { Fazla kilolu ve obez } \\
35-55 \text { yaş }\end{array}$ & $\begin{array}{l}\text { Yamax Digiwalker SW- } \\
200 \\
12 \text { hafta } \\
\text { Grup 1: } 30 \text { dk yürüyüş } \\
\text { Grup 2: } 10000 \\
\text { adım/gün }\end{array}$ & $\begin{array}{l}\text { İki grup arasında antropometrik ve kan } \\
\text { basıncı değerlerinde anlamlı farklılık yok, } \\
\text { Günde } 10000 \text { adımdan fazla atan grubun } \\
\text { adım sayıları̈da \% } 43 \text { artış, } \\
30 \text { dk yürüyüş yapan grubun adım } \\
\text { sayılarında \%35 oranında artış, } \\
\text { Halk sağlığı kampanyalarında günde } 10000 \\
\text { adım hedefinin motivasyonel bir öneri } \\
\text { olabileceği belirtilmiş. }\end{array}$ \\
\hline
\end{tabular}

BMH: bazal metabolik hiz; DM: diabetes mellitus; FA: Fiziksel aktivite; HT: hipertansiyon; RPE: algılanan zorluk derecesi; VYY: vücut yağ yüzdesi

\section{Adım Sayısı Ölçümü}

Kronik hastalıkların prevelansının azaltılması, sağlığın korunması ve geliștirilmesinde FA ölçümünü doğru yapmak ve önerilerde bulunmak önemlidir. Özellikle sedanter yaşam tarzı olan bireyler için adım sayısı önemli bir gösterge olarak kabul edilmektedir (30). Fiyatı, mekanizması ve özelliğine (saat, hafıza, yazılım vb.) göre değișebilen pedometreler, dikey olarak yapılan hareketleri içindeki akseloremetre aracılığıyla ölçen cihazlardır. Adım sayısının ölçümünde tek ve çoklu eksende ölçüm yapabilen, farklı marka ve özelliklerde birçok pedometre ve akselerometre kullanılmaktadır. Teknolojiyle birlikte akıllı telefon uygulamalarında yer alan adım sayısı programları, kol bantları, saatler gibi mikro teknolojik araçlar da adım sayısını belirleyen diğer yöntemlerdir (80). Pedometrelerin ve akselerometrelerin her birinin avantaj ve dezavantajı bulunmaktadır. Araştırmanın amacına göre ölçüm aracını belirlerken; ölçüm aracının güvenirliği, geçerliği, grubun büyüklügü̈, yaş, cinsiyet, eğitim düzeyi, zaman, maliyet, bireyler tarafından kabul edilebilirliği ve komorbidite gibi unsurlar göz önünde bulundurulmalıdır. Ayrıca cihazın yerleștirildiği bölge (bel, uyluk, cep, el ve ayak bileği vb) ve cihazı takma süresi gibi faktörler de adım sayısı verilerinin düşük veya yüksek çıkmasına neden olabileceğinden, yorumlanması $(3,33,52,80)$.

\section{SONUÇ}

Sağlığın korunmasında ve geliştirilmesinde, kronik hastalık prevelansının azaltılmasında "aktif yaşam" alışkanlı̆̆ kazanmak önemlidir. Aktif bir yaşam için motivasyonel bir öneri olan 10000 adım hedefine tek bir aktivite süresinde ulaşmak zordur. Önerilen adım sayısına ulaşmak ve sedanter yaşamı en aza indirmek için gün içinde de "aktif" olmak gereklidir. Ekran karşısında uzun süre oturmamak, belirli aralıklarla kısa yürüyüşler yapmak, kısa mesafelere yürüyerek gitmek gibi pratik önerilerle sedanter yaşam tarzı en aza indirilerek bir günlük adım sayısı açığı kapatılabilmektedir. Bununla birlikte, sağlıklı yaşam için temel prensip olarak, bireyin orta şiddette ve sevdiği bir aktiviteyi yapması önerilmektedir. Bu doğrultuda, yetişkinler için FA rehberleri ile uyumlu olarak, dakikada 100 adım veya 30 dakikada 3000-3500 adım (1000 adım/10 dk x 3) atılarak orta şiddette bir aktivite programı hazırlanabilir ve daha az adım atılarak da sağlık faydası elde edilebilir. Sağlık profesyonelleri için FA verilerinin takibinde adım sayısı önemli bir gösterge olabilir. Klinik uygulamalarda giyilebilir tıbbi fiziksel aktivite 
ölçüm cihazları veya adım ölçerlerin henüz yaygınlaşmadığ 1 görülmektedir. Geçerliği ve güvenirliği olan giyilebilir tıbbi ölçüm araçlarının geliştirilmesi, özellikle yürüme alışkanlığı değişen yaşlı ve engelli bireyler için büyük önem taşıdığından, belirli hastalıkların tedavi sürecine adım sayısı da entegre edilebilir. $\mathrm{Bu}$ doğrultuda, yaşlı ve kronik hastalığı olan bireyler için de bir adım sayısı indeksinin geliştirilmesi uygun olacaktır. Sedanter yaşam tarzını azaltmak için uluslararası fiziksel aktivite envanterleri ile pedometre aracılığıyla ölçülen adım sayısı arasındaki ilişkinin araştırılması yönünde daha fazla çalışma yapılması, adım sayısı önerisinde bulunurken yaş, cinsiyet, eğitim, meslek ve komorbidite varlı̆̆ gibi faktörlerin de göz önüne alınarak ulaşılabilir gerçekçi hedefler konması gerekmektedir.

\section{KAYNAKLAR}

1. Caspersen CJ, Powell KE, Christenson GM. Physical activity, exercise, and physical fitness: definitions and distinctions for health-related research. Public Health Rep. 1985;100(2):126-31.

2. Owen N, Sparling PB, Healy GN, et al. Sedentary behavior: emerging evidence for a new health risk. Mayo Clin Proc. 2010a;85(12):1138-41.

3. Sitthipornvorakul E, Janwantanakul P, J van der Beek A. Correlation between pedometer and the Global Physical Activity Questionnaire on physical activity measurement in office workers. BMC Res Notes. 2014;7:280.

4. Jans MP, Proper KI, Hildebrandt VH. Sedentary behavior in Dutch workers: differences between occupations and business sectors. Am J Prev Med. 2007;33:450-4.

5. Picavet HS, Pas LW, van Oostrom $\mathrm{SH}$, et al. The relation between occupational sitting and mental, cardiometabolic, and musculoskeletal health over a period of 15 years--the doetinchem cohort study. PLoS One. 2016;11;11(1):e0146639.

6. Dunstan DW, Howard B, Healy GN, et al. Too much sitting - a health hazard. Diabetes Res Clin Pract. 2012;97(3):368-76.

7. Gibbs BB, Hergenroeder AL, Katzmarzyk PT, et al. Definition, measurement, and health risks associated with sedentary behavior. Med Sci Sports Exerc. 2015;47(6):1295-300.

8. Pate RR, O'Neill JR, Lobelo F. The evolving definition of "sedentary". Exerc Sport Sci Rev. 2008;36(4):173-8.

9. Biddle SJ. Sedentary Behavior. Am J Prev Med. 2007;33(6):502-4.
10. Tudor-Locke C, Craig CL, Brown WJ, et al. How many steps/day are enough? For adults. Int J Behav Nutr Phys Act. 2011;28:8:79.

11. Sedentary Behaviour Research Network. Letter to the editor: standardized use of the terms "sedentary" and "sedentary behaviours". Appl Physiol Nutr Metab. 2012;37(3):540-2.

12. Tremblay MS, Aubert S, Barnes JD, et al. Sedentary behavior research network (sbrn)- terminology consensus project process and outcome. Int J Behav Nutr Phys Act. 2017;10:14(1):75.

13. Owen N, Healy GN, Matthews CE, et al. Too much sitting: the population health science of sedentary behavior. Exerc Sport Sci Rev. 2010b;38(3):105-13.

14. http://new.who.int/news-room/factsheets/detail/physical-activity. Erişim tarihi: 20.06.2018.

15. Garber CE, Blissmer B, Deschenes MR, et al. American College of Sports Medicine position stand. Quantity and quality of exercise for developing and maintaining cardiorespiratory, musculoskeletal, and neuromotor fitness in apparently healthy adults: guidance for prescribing exercise. Med Sci Sports Exerc. 2011;43(7):1334-59.

16. Haskell WL, Lee IM, Pate RR, et al. Physical activity and public health: updated recommendation for adults from the American College of Sports Medicine and the American Heart Association. Med Sci Sports Exerc. 2007;39:1423-34.

17. World Health Organization. Global Recommendations on Physical Activity for Health. 2010.

18. http://www.exerciseismedicine.org/support_page.php /about. Erişim tarihi 26.06.2018.

19. http://www.egzersizilactir.org.tr. Erişim tarihi: 25.06.2018.

20. Bravata DM, Spangler CS, Sundaram V, et al. Using pedometers to increase physical activity and improve health: a systematic review. JAMA. 2007;298(19):2296304.

21. Tudor-Locke C, Bassett DR Jr. How many steps/day are enough? Preliminary pedometer indices for public health. Sports Med. 2004;34:1-8.

22. Choi BC, Pak AW, Choi JC, et al. Daily step goal of 10,000 steps: a literature review. Clin Invest Med. 2007;30(3): 146-51.

23. Tudor-Locke C, Washington TL, Hart TL. Expected values for steps/day in special populations. Preventive Medicine. 2009;49(1):3-11.

24. Tudor-Locke C, Sisson SB, Collova T, et al. Pedometer determined step count guidelines for classifying walking intensity in a young ostensibly healthy population. Can J Appl Physiol. 2005;30:666-76.

25. Beets MW, Agiovlasitis S, Fahs CA, et al. Adjusting step count recommendations for anthropometric variations in leg length. J Sci Med Sport. 2010;13(5):509-12. 
26. Abel M, Hannon J, Mullineaux D, et al. Determination of step rate thresholds corresponding to physical activity classifications in adults. J Phys Act Health. 2011;8:4551.

27. Marshall SJ, Levy SS, Tudor-Locke CE, et al. Translating physical activity recommendations into a pedometerbased step goal: 3000 steps in 30 minutes. Am J Prev Med. 2009;36:410-5.

28. Rowe DA, Welk GJ, Heil DP, et al. Stride rate recommendations for moderate intensity walking. Med Sci Sports Exerc. 2011;43:312-8.

29. Pal S, Cheng C, Ho S. The effect of two different health messages on physical activity levels and in sedentary overweight, middle-aged women. BMC Public Health. 2011;11:204.

30. Tudor-Locke C, Craig CL, Aoyagi Y, e al. How many steps/day are enough? For older adults and special populations. Int J Behav Nutr Phys Act. 2011;28;8:80.

31. Miller R, Brown W. Meeting physical activity guidelines and average daily steps in a working population. J Phys Act Health. 2004;1:218-26.

32. Behrens TK, Hawkins SB, Dinger MK. Relationship between objectively measured steps and time spent in physical activity among free-living college students. Meas Phys Educ Exerc Sci. 2005;9:67-77.

33. Tudor-Locke C, Craig CL, Thyfault JP, et al. A stepdefined sedentary lifestyle index: $<5000$ steps/day. Appl Physiol Nutr Metab. 2013;38(2):100-14.

34. Tudor-Locke C, Craig CL, Beets MW, et al. How many steps/day are enough? for children and adolescents. Int J Behav Nutr Phys Act. 2011;28;8:78.

35. Duncan JS, Hopkins WG, Schofield G, et al. Effects of weather on pedometer-determined physical activity in children. Med Sci Sports Exerc. 2008;40(8):1432-8.

36. Karaca A. Yetişkin bireylerde orta ve yüksek şiddetli fiziksel aktivitenin cinsiyete göre incelenmesi. Spor Bilimleri Dergisi. 2008;19(1):54-62.

37. Can S, Arslan E, Ersöz G. Güncel bakış açısı ile fiziksel aktivite. Ankara Üniv Spor Bil Fak. 2014;12 (1):1-10.

38. Can S, Arslan E, Ersöz G. Cronic Diseases and Exercises. SSTB International Refereed Academic Journal of Sports. 2015;5(16):136-67.

39. Mantovani AM, Duncan S, Codogno JS, et al. Different amounts of physical activity measured by pedometer and the associations with health outcomes in adults. $J$ Phys Act Health. 2016;13(11):1183-91.

40. Dasgupta K, Joseph L, Pilote L, et al. Daily steps are low year-round and dip lower in fall/winter: findings from a longitudinal diabetes cohort. Cardiovasc Diabetol. 2010;9:81.

41. Yasunaga A, Togo F, Watanabe E, et al. Sex, age, season, and habitual physical activity of older Japanese: the Nakanojo study. J Aging Physical Act. 2008;16(1):3-13.

42. Mitsui T, Barajima T, Kanachi M, et al. Daily walking activity among male office workers in a rural town in northern Japan. J Physiol Anthropol. 2010;29(1):43-6.
43. Newton JL, Bhala N, Burt J, et al. Characterisation of the associations and impact of symptoms in primary biliary cirrhosis using a disease specific quality of life measure. J Hepatol. 2006;44:776-83.

44. Azevedo MR, Araújo CL, Silva MCD, et al. Tracking of physical activity from adolescence to adulthood: a population-based study. Rev Saude Publica. 2007;41:69-75.

45. Sisson SB, Camhi SM, Tudor-Locke C, et al. Characteristics of step-defined physical activity categories in U.S. Adults. Am J Health Promot. 2012;26(3):152-9.

46. Dwyer T, Ponsonby AL, Ukoumunne OC, et al. Association of change in daily step count over five years with insulin sensitivity and adiposity: population based cohort study. BMJ. 2011; 342: 7249.

47. Bohannon RW. Number of pedometer-assessed steps taken per day by adults: A descriptive meta-analysis. Phys Ther. 2007;87(12):1642-50.

48. Schmidt MD, Cleland VJ, Shaw K, et al. Cardiometabolic risk in younger and older adults across an index of ambulatory activity. Am J Prev Med. 2009;37(4):278-84.

49. Clemes SA, Hamilton SL, Griffiths PL. Summer to winter variability in steps counts of normal weight and overweight adults living in the U.K. J Phys Act Health. 2011;8:36-44.

50. Can S, Karaca A, Arslan E, et al. Physical activity measurement by SWA in employees: weekdays and weekend. Physical Activity Review. 2017;5:167-75.

51. Hirvensalo M, Telama R, Schmidt MD, et al. Daily steps among Finnish adults: Variation by age, sex, and socioeconomic position. Scand J Public Health. 2011;39(7):669-77.

52. Tudor-Locke C, Johnson WD, Katzmarzyk PT. Relationship between accelerometer-determined steps/day and other accelerometer outputs in U.S. adults. J Phys Act Health. 2011d;8:410-19.

53. Fukuoka Y, Nakagawa Y, Ogoh K, et al. Dynamics of the heart rate response to sinusoidal work in humans: influence of physical activity and age. Clin Sci. 2002;102: 31-8.

54. Demirci, N. Okul dışı sportif etkinliklere katılan 11-13 yaşları arasındaki çocukların okul içi ve okul dışı adım sayılarının incelenmesi. Hacettepe Üniversitesi Spor Bilimleri ve Teknolojisi Programı Yüksek Lisans Tezi. Ankara: Hacettepe Üniversitesi; 2017.

55. Burns RD, Brusseau TA, Hannon JC. Prediction of optimal daily step count achievement from segmented school physical activity. Advances in Public Health. 2015;1-6.

56. Tudor-Locke C, Bassett DR, Rutherford WJ, et al. BMI referenced cut points for pedometer-determined steps per day in adults. J Phys Act Health. 2008;5(Suppl 1):126-39.

57. Can S, Gündüz N, Arslan E, et al. Multi-Instrument assessment of physical activity in female office 
workers. Int $J$ Occup Med Environ Health. 2016;29(6):937-45.

58. Can S, Arslan E, Biernat E, et al. Different physical activity guidelines and its association with sociodemographic and anthropometric characteristics among working women. Balt J Health Phys Activ. 2017b;9(3):115-23.

59. DePew Z, Novotny P, Benzo R. How many steps are enough to avoid severe physical inactivity in patients with chronic obstructive pulmonary disease? Respirology. 2012;17(6):1026-7.

60. Moy ML, Danilack VA, Weston NA, et al. Daily step counts in a US cohort with COPD. Respir Med. 2012;106(7):962-9.

61. Van Sloten TT, Savelberg HH, Duimel-Peeters IG, et al. Peripheral neuropathy, decreased muscle strength and obesity are strongly associated with walking in persons with type 2 diabetes without manifest mobility limitations. Diabetes Res Clin Pract. 2011;91(1):32-9.

62. Naal FD, Impellizzeri FM. How active are patients undergoing total joint arthroplasty?: A systematic review. Clin Orthop Relat Res. 2010;468(7):1891-904.

63. Vanhecke TE, Franklin BA, Zalesin KC, et al. Cardiorespiratory fitness and obstructive sleep apnea syndrome in morbidly obese patients. Chest. 2008;134(3):539-45.

64. Damschroder LJ, Lutes LD, Goodrich DE, et al. A smallchange approach delivered via telephone promotes weight loss in veterans: Results from the ASPIRE-VA pilot study. Patient Educ Couns. 2010;79(2):262-6.

65. Maraki MI, Aggelopoulou N, Christodoulou N, et al. Lifestyle intervention leading to moderate weight loss normalizes postprandial triacylglycerolemia despite persisting obesity. Obesity (Silver Spring). 2011;19(5):968-76.

66. McKercher CM, Schmidt MD, Sanderson KA, et al. Physical activity and depression in young adults. $\mathrm{Am} \mathrm{J}$ Prev Med. 2009;36(2):161-4.

67. Krumm EM, Dessieux OL, Andrews $P$, et al. The relationship between daily steps and body composition in postmenopausal women. J Womens Health. 2006;15(2):202-10.

68. Freak-Poli RL, Wolfe R, Walls $H$, et al. Participant characteristics associated with greater reductions in waist circumference during a four-month, pedometerbased, workplace health program. BMC Public Health. 2011;11:824.
69. Van Dyck D, De Greef K, Deforche B, et al. The relationship between changes in steps/day and health outcomes after a pedometer-based physical activity intervention with telephone support in type 2 diabetes patients. Health Educ Res. 2013;28(3):539-45.

70. Gray SR, Baker G, Wright A, et al. The effect of a 12 week walking intervention on markers of insulin resistance and systemic inflammation. Prev Med. 2009;48(1):39-44.

71. Mendoza L, Horta P, Espinoza J, et al. Pedometers to enhance physical activity in COPD: A randomised controlled trial. Eur Respir J. 2015;45(2):347-54.

72. Araiza P, Hewes H, Gashetewa C, et al. Efficacy of a pedometer-based physical activity program on parameters of diabetes control in type 2 diabetes mellitus. Metabolism. 2006;55(10):1382-7.

73. Schneider PL, Bassett DR Jr, Thompson DL, et al. Effects of a 10,000 steps per day goal in overweight adults. Am J Health Promot. 2006;21(2):85-9.

74. Dasgupta K, Rosenberg E, Joseph L, et al. Physician step prescription and monitoring to improve ARTERial health (SMARTER): A randomized controlled trial in patients with type 2 diabetes and hypertension. Diabetes Obes Metab. 2017;19(5):695-704.

75. Guglani R, Shenoy S, Sandhu JS. Effect of progressive pedometer based walking intervention on quality of life and general well being among patients with type 2 diabetes. J Diabetes Metab Disord. 2014;13(1):110.

76. Johnson ST, Bell GJ, McCargar LJ, et al. Improved cardiovascular health following a progressive walking and dietary intervention for type 2 diabetes. Diabetes Obes Metab. 2009;11:836-43.

77. Iwane M, Arita M, Tomimoto S, et al. Walking 10,000 steps/ day or more reduces blood pressure and sympathetic nerve activity in mild essential hypertension. Hypertens Res. 2000; 23:573-80.

78. De Greef K, Deforche B, Tudor-Locke C, et al. A cognitivebehavioural pedometer-based group intervention on physical activity and sedentary behaviour in individuals with type 2 diabetes. Health Educ Res. 2010;25(5):724-36.

79. Kroemeke A, Zając-Gawlak I, Pośpiech D, et al. Postmenopausal obesity: 12,500 steps per day as a remedy? Relationships between body composition and daily steps in postmenopausal women. Prz Menopauzalny. 2014;13(4):227-32.

80. Karaca A. Fiziksel aktivite değerlendirme yöntemleri. 1. Basım. Ankara: Spor Yayınevi ve Kitabevi; 2017. 